\title{
Implementasi E-CRM berbasis Web pada Perpustakaan Digital Sekolah Gema Nurani
}

\section{Web-based E-CRM Implementation At Gema Nurani School Digital Library}

\author{
Siti Nurajizah \\ Universitas Bina Sarana Informatika, Jl Kamal Raya No 18, Ringroad Barat, \\ Cengkareng, Jakarta Barat (021)54376399 \\ Program Studi Sistem Informasi, Universitas Bina Sarana Informatika \\ siti.snz@bsi.ac.id
}

\begin{abstract}
Abstrak
Perpustakaan adalah salah satu lembaga pelayanan publik yang cukup penting di dalam sekolah. Pelayanan yang diberikan mencakup semua ruang lingkup informasi seputar perpustakan. Sekolah Gema Nurani telah memiliki perpustakaan digital berbasis web, database yang dibangun untuk memudahkan pendokumentasian data serta memberikan kemudahan dalam pengelolaan data perpustakaan. Bertambahnya koleksi buku di perpustakaan, tidak diimbangi dengan kesigapan petugas dalam melakukan pembaharuan data, hal ini menjadikan kesulitan tersendiri bagi pengunjung website untuk mencari buku yang diinginkan. Pengunjung website juga tidak dapat memberikan masukan untuk peningkatan kualitas website serta pelayanan petugas perpustakaan. Website yang ada selama ini hanya memberikan informasi satu arah yaitu dari pihak perpustakaan saja tanpa adanya ruang bagi pengunjung untuk memberikan saran dan kritik bagi pengembangan website. Konsep Customer Relationship Management (CRM) merupakan teknik yang dapat digunakan untuk memperoleh, mengkonsolidasi, serta menganalisa data yang digunakan sebagai sarana interaksi dengan customer yaitu pengunjung/anggota perpustakaan sehingga akan terwujud pandangan yang bersifat ensiklopedis terhadap pengguna. E-CRM diterapkan pada perpustakaan digital Sekolah Gema Nurani agar meningkatkan hubungan baik, dedikasi serta loyalitas pengguna perpustakaan sebagai upaya pihak sekolah untuk menumbuhkan dan meningkatkan minat membaca pengunjung. Metode penelitian yang digunakan untuk pengembangan sistem informasi ini adalah metodologi proses pengembangan sistem FAST( Framework for the Aplication of System Thinking) dengan pendekatan Model Driven Development Sytategy karena metode FAST standarisasinya baik serta proses yang stabil dan terencana.
\end{abstract}

Kata kunci-E-CRM, Perpustakaan Digital, FAST

\begin{abstract}
The library is one of the important public service institutions in the school. The services provided cover all the scope of information about libraries. Gema Nurani School already has a digital library, a database built to facilitate data documentation and provide ease in library data management. Increased collection of books, not matched by the alertness of officers in updating the data, this makes its own difficulties for website visitors to find the desired book. Visitors also cannot provide input for improving the quality of the website and the services of library staff. The website so far only provided one-way information, from the library alone without any space for visitors to provide advice and criticism for website development. The concept of Customer Relationship Management (CRM) is a technique that can be used to
\end{abstract}


obtain, consolidate, and analyze data used as a means of interaction with customers, visitors / members of the library so that an encyclopedic view of the user will be realized. E-CRM is applied to the digital library of the Gema Nurani School in order to improve good relations, dedication and loyalty of library users as an effort of the school to grow up and increase interest in reading. In this research, the research method used for the development of this information system is the methodology for developing system FAST (Framework for the Application of System Thinking) with a Model Driven Development Sytategy approach because the standard FAST method is good as well as a stable and planned process

Keywordsi-E-CRM, Digital Library, FAST

\section{PENDAHULUAN}

Teknologi informasi saat ini berkembang dengan cukup pesat. Hampir semua aspek kehidupan sudah menggunakan kecanggihan teknologi informasi. Tidak terkecuali pada bidang pendidikan. Sistem informasi bukanlah hal yang asing dalam dunia pendidikan. Implementasi dari kemajuan teknologi informasi dapat terlihat dengan penggunaan sistem informasi maupun proses pengolahan data di lembaga-lembaga pemerintah maupun swasta pada bidang pendidikan.

Perpustakaan digital merupakan salah satu implementasi dari perkembangan teknologi informasi. Keberadaan perpustakaan digital sebagai salah satu lembaga pelayanan publik, diharapkan menjadi sarana pemenuhan kebutuhan dalam mencari sumber referansi berupa literatur seperti buku, majalah, ensiklopedia dan media bacaan lainnya yang mendukung proses belajar mengajar. Perpustakaan juga diharapkan dapat memberikan pelayanan prima terhadap pemenuhan kebutuhan anggota/pengguna perpustakaan.

Sekolah Gema Nurani merupakan sekolah yang terdiri dari tingkat TK, SD, SMP dan SMA dan telah mempunyai sebuah perpustakaan digital yang telah menerapkan sentralisasi database guna memudahkan proses dokumentasi data sehingga memberikan kemudahan dalam pengelolaan data buku, data anggota, data peminjaman dan pengembalian serta dapat menghasilkan sebuah laporan yang cepat, tepat dan akurat yang membuat proses pekerjaan administratif perpustakaan menjadi lebih efektif dan efisien. Namun, peningkatan fungsi perpustakaan digital serta kemudahan dalam mengaksesnya belum dapat menjadi suatu nilai tambah terhadap kepuaasan pengguna.

Berdasarkan pengamatan yang telah dilakukan, nampak terlihat bahwa petugas kurang melakukan pembaharuan data pada website perpustakaan sehingga pengunjung tidak dapat menemukan koleksi yang diinginkan atau tidak dapat mengetahui keberadaan koleksi yang ingin dipinjam. Pengunjung juga tidak dapat memberikan masukan baik saran maupun kritik terhadap website. Pengelola perpustakaan kurang mengetahui secara rinci berapa jumlah pengunjung di website tersebut. Secara tidak sadar, hal ini dapat menjadikan hubungan antara petugas perpustakaan dengan pengunjung tidak terjalin dengan baik. Selain itu, jumlah pengguna yang banyak merupakan tantangan tersendiri bagi pihak perpustakaan untuk tetap memberikan pelayanan terbaik mereka. Ternyata hal ini dapat menjadi boomerang tersendiri bagi pihak pengelola perpustakaan, dimana banyaknya jumlah pengguna website perpustakaan belum dapat diimbangi dengan kualitas pelayanan yang memadai terhadap pengguna perpustakaan digital.

Melihat dari permasalahan yang telah disebutkan diatas, perlu diterapkan sebuah strategi manajemen yang tepat agar tercipta hubungan yang baik antara pengguna/pengunjung perpustakaan dengan pihak pengelola perpustakaan.

\section{METODE PENELITIAN}

Konsep Customer Relationship Management (CRM) merupakan sebuah inovasi baru 
yang mulai banyak digunakan dalam menjaga hubungan dengan pelanggan. Sistem CRM merupakan strategi yang digunakan untuk mempelajari kebutuhan dan perilaku pelanggan untuk membangun relasi yang kuat dengan pelanggan[1].

CRM adalah salah satu teknik yang bisa digunakan untuk memperoleh, mengkonsolidasi, menganalisa data yang kemudian digunakan sebagai sarana interaksi dengan customer(penggunan perpustakaan: guru, siswa, karyawan sekolah) sehingga tercipta suasana ensiklopedis terhadap customer serta adanya hubungan baik antara customer dengan pelaku kegiatan pemilik usaha [2].

Menurut Kurniawan dalam [3], "Kerangka komponen CRM diklasifikasikan menjadi tiga yaitu":

1. Pengoperasian CRM: Pengoperasian CRM merupakan garda depan dalam pelayanan. Interaksi dengan konsumen merupakan bagian dari kegiatan CRM. Penggunaan fasilitas aplikasi web menjadi salah satu otomasi pelayanan proses bisnis pemasaran.

2. Analitikal CRM: memahami kebutuhan pelanggan merupakan bagian dari kegiatan bagian administrasi. Tren Pasar, perilaku konsumen dan Analisa kebutuhan konsumen menjadi dasar acuan kegiatan analitikal CRM. Data yang digunakan bersumber pada data yang diperoleh dari kegiatan operasional.

3. Collaborative CRM: email, komunitas, dan sejenisnya digunakan untuk berinteraksi antara konsumen dan Perusahaan. Hal ini bertujuan untuk menjaga kesetiaan konsumen. Word of mouth (WOM) memberikan stimulus bagi konsumen atas produk yang digunakan menjadi rekomendasi untuk dimiliki atau digunakan sehingga menjadi daya tarik bagi komsumen lain untuk membeli.

Pengenbangan CRM dibidang teknologi informasi adalah dengan adanya konsep Electronic Customer Relationship Management (E-CRM). Konsep E-CRM merupakan salah satu alternatif yang diterapkan pada perpustakaan digital Sekolah Gema Nurani dengan maksud untuk meningkatkan dedikasi serta loyalitas pengguna perpustakaan sebagai upaya pihak sekolah untuk menumbuhkan dan meningkatkan minat membaca. Hasil dari penelitian yang penulis lakukan diharapkan akan menumbuhkan minat membaca serta memberikan kemudahan bagi pengguna atau anggota perpustakaan dalam mengaskses informasi yang ada pada website perpustakaan Sekolah Islam Gema Nurani.

Dalam penelitian ini menerapkan metode pengembangan sistem informasi dengan mengimplementasikan metodologi proses pengembangan sistem yang disebut dengan FAST( Framework for the Aplication of System Thinking) dengan pendekatan Model Driven Development Sytategy dengan alasan karena metode FAST standarisasinya baik serta proses yang stabil dan terencana[3]. Model sistem ini memfasilitasi kemudahan komunikasi antara user sistem, analisis sistem, sistem desainer dan sistem builder. Menurut Whitten dalam [3], "Dalam metode FAST digunakan untuk mengkomunikasikan dan mengilustrasikan pengetahuan, proses, interface building block dari sistem informasi, pendekatan ini disebut model driven development". Berikut ini adalah gambar mengenai tahapan-tahapan pengembangan pada metode FAST: 


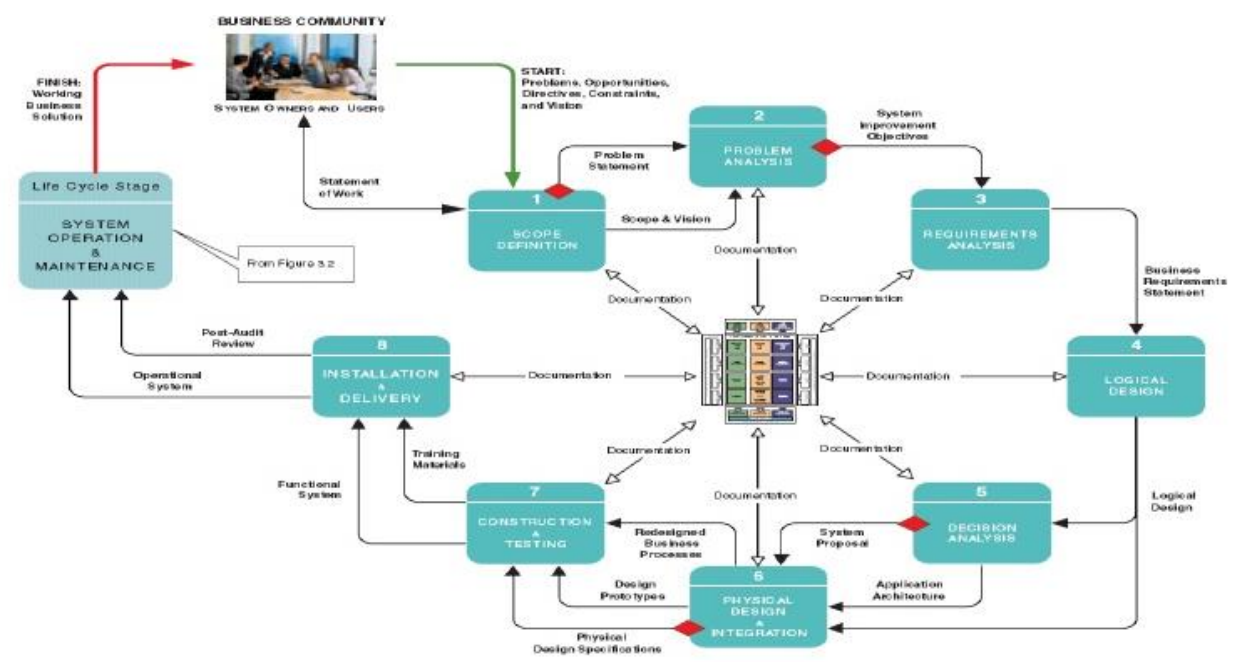

Gambar 1 Metode Pengembangan Sistem FAST

Berikut ini adalah fase pengembangan dalam metode FAST[4]:

1. $\quad$ Scope Definition (Definis Lingkup)

Pada tahap ini dilakukan langkah awal untuk proses perancangan sistem informasi dengan menambahkan konten baru pada bagiam website perpustakaan.

2. Problem Analysis (Analisis Permasalahan)

Pada tahap ini akan dilakukan penyelidikan terhadap masalah yang muncul pada sistem informasi perpustakaan yang sebelumnya. Diharapkan hasil dari tahapan ini adalah perbaikan pelayanan perpustakaan digital bagi pengguna/anggota perpustakaan.

3. Requirements Analysis (Analisa Kebutuhan)

Pada tahap ini dilakukan proses identifikasi data, proses serta interface yang dibutuhkan untuk melengkapi konten di dalam website perpustakaan digital ini.

4. $\quad$ Logical Design (Desain Logis)

Penggambaran Entity Relationship Diagram dalam sistem perpustakaan digital merupakan suatu proses fungsional yang dihubungkan dengan alur data secara terkomputerisasi.

5. Decision Analysis (Analisis Keputusan)

Tahapan ini ditujukan untuk memilih beberapa kandidat dari perangkat lunak dan perangkat keras yang akan dipilih dan dipergunakan dalam implementasi sistem sebagai solusi terhadap tahapan-tahapan sebelumnya.

6. $\quad$ Physical Design (Desain Logis)

Tujuan dari tahapan ini adalah mentransformasi kebutuhan bisnis yang direpresentasikan sebgai logical design menjadi physical design yang akan dijadikan sebagai rujukan dalam membuat konten tambahan terhadap sistem perpustakaan digital tersebut

7. Construction and Testing

Setelah membuat physical design, maka akan dimulai menkonstruksi dan melakukan uji coba terhadap sistem yang memenuhi kebutuhan bisnis dan spesifikasi sistem. Setelah dilakukan uji coba terhadap sistem dalam hal ini adalah penambahan konten dalam web perpustakaan digital maka sistem siap untuk diimplementasikan.

8. $\quad$ Installation and Delivery

Pada tahap ini akan mulai dipergunakan sistem perpustakaan digital yang sudah memiliki tambahan konten berupa polling untuk mengetahui tentang informasi yang ada pada web perpustakaan dapat diterima dengan baik atau tidak.

Teknologi Informasi 
Semakin meningkatnya perkembangan teknologi informasi, perpustakaan diharapkan dapat menjadi sarana penyedia sumber-sumber informasi dalam bentuk elektronik. Pemanfaatan informasi dalam bentuk elektronik saat ini sudah menjadi bagian dari gaya hidup modern masyarakat. Hal ini harus dilakukan untuk memenuhi tuntutan terhadap mutu layanan perpustakaan, resource sharing, mengefektifkan SDM, efisiensi waktu dan keragaman informasi yang dikelola[5].

Implementasi teknologi informasi pada perpustakaan dipengaruhi oleh beberapa faktor yaitu:1.) kemudahan mendapatkan produk teknologi informasi, 2.) harga semakin terjangkau untuk memperoleh produk teknologi informasi, 3.) kemampuan dari teknologi informasi, 4.) tuntutan layanan masyarakat serba "klik", 5.) mengefisiensikan dan mempermudah pekerjaan dalam perpustakaan memberikan layanan yang lebih baik kepada pengguna perpustakaan meningkatkan citra perpustakaan, 6.) pengembangan infrastruktur nasional, regional dan global [6]

\section{E-CRM}

E-CRM merupakan singkatan dari Electronic Customer Relationship Management merupakan strategi yang menggunakan teknologi informasi yang memberikan perpustakaan suatu pandangan customer (pengguna perpustakaan: siswa, mahasiswa, guru, dosen, dan masyarakat) secara luas, yang dapat dihandalkan dan berintegrasi sehingga semua proses dan interaksi customer (pengguna perpustakaan: siswa, mahasiswa, guru, dosen, dan masyarakat) membantu dalam mempertahankan minat membaca dan memperluas hubungan yang menguntungkan secara bersama [6]. Banyak organisasi yang memiliki spesifikasi baik tentang E-CRM atau karyawan yang memiliki tanggung jawab penuh terhadap E-CRM, dimana keduanya (CRM dan E-CRM)bukan hanya tentang teknologi dan database, bukan hanya tentang proses atau hanya tentang melakukan sesuatu tetapi tentang bagaimana memenuhi tuntutan, kebutuhan dan keinginan pelanggan[8]. Keuntungan dari konsep E-CRM yaitu terciptanya hubungan yang baik dengan pengguna perpustakaan(guru, siswa, karyawan sekolah) dalam kurun waktu yang relatif lama.

\section{Fase - fase CRM}

Terdapat tiga fase yang digunakan dalam pengelolaan daur hidup pelanggan[7], seperti:

1. Acquire

Pada tahap ini perpustakaan akan mendapatkan pelanggan/anggota baru melalui informasi yang diberikan oleh petugas perpustakaan serta informasi dari web perpustakaan.

\section{Enchane}

Merupakan tahapan dimana pihak perpustakaan berusaha untuk menjalin hubungan dengan pengunjung maupun anggota perpustakaan melalui pemberian pelayanan yang baik terhadap pengunjung dan anggota.

\section{Retain}

Pada tahap ini dapat membantu pihak perpustakaan secara proaktif dan memberikan reward kepada pengunjung maupun anggota yang memiliki loyalits cukup tinggi.

\section{HASIL DAN PEMBAHASAN}

Implementasi komsep E-CRM yang menjadi sarana untuk meningkatkan informasi dalam proses pelayanan perpustakaan digital Gema Nurani bertujuan sebagai sarana untuk mengetahui bagaimana cara perpustakaan sekolah dapat meningkatkan pelayanan perpustakaan terhadap pengguna(Guru, Siswa dan karyawan). Pelayanan perpustakaan dapat ditingkatkan melalui penerapan bentuk digitalisasi yang telah diterapkan pada Sekolah serta adanya peningkatan sistem dengan menerapkan konsep E-CRM. Penelitian yang dibuat akan menghasilkan sebuah aplikasi berbasis web yang dapat digunakan oleh pihak sekolah sebagai sarana pelayanan prima dibidang perpustakaan sehingga akan tercipta kepuasan pengguna 
terhadap pelayanan perpustakaan Sekolah Gema Nurani. Konsep E-CRM yang dibuat untuk perpustakaan Sekolah Gema Nurani dapat dipergunakan oleh guru, siswa dan warga sekolah sebagai sarana untuk pencarian sumber referensi media baca ataupun literatur dalam penunjang proses belajar mengajar sehingga akan meningkatkan jumlah pengunjung perpustakaan.

Penelitian ini menghasilkan sebuah perangkat lunak berupa aplikasi perpustakaan digital yang digunakan untuk peningkatan kapabilitas kinerja pelayanan perpustakaan dan mengaktualisasikan terwujudnya perpustakaan berbasis digital dengan menerapkan konsep ECRM, yaitu: 1) kemudahan bagi pengguna layanan perpustakaan dalam mencari informasi terkait bahan pustaka yang dibutuhkan secara online sehingga pengguna dapat merasakan kepuasan terhadap pelayanan yang diberikan serta kemudahan dan kenyamanan dengan adanya penerapan E-CRM, sehingga dapat menambah animo para pengguna untuk meningkatkan antusiasme terhadap minat baca pengunjung, 2)kemudahan akses informasi terkait perpustakaan dapat diakses setiap saat tanpa adanya batas ruang dan waktu. 3)petugas perpustakaan dapat melakukan monitoring terhadap pelayanan perpustakaan, hal ini diperlukan untuk mengamati adakah ketidakpuasan dari pengguna sehingga dapat dengan cepat diproses dan dijadikan evaluasi untuk perbaikan sistem informasi perpustakaan, 4) pengguna perpustakaan secara berkesinambungan akan mendapatkan informasi terkini terkait data perpustakaan. Misalnya ada buku terbitan terbaru, kamus baru, majalah baru, ensiklopedia terbaru. Dengan akses informasi terbaru secara tepat waktu maka akan dapat meningkatkan antusiasme pengunjung dalam budaya membaca.

3.1 Analisa Kebutuhan

1. Analisa Kebutuhan Pengguna

a. Skenario kebutuhan petugas: 1.) Mengelola data anggota, 2.) mengelola data buku, 3.) mengelola data peminjaman dan pengembalian, 4.) mencetak laporan peminjaman dan pengembalian. 5.) menampilkan grafik kepuasan pengunjung/anggota.

b. Skenario kebutuhan anggota maupun pengguna perpustakaan: 1.) melakukan peminjaman, 2.) melakukan pencarian data buku, 3.) melihat data peminjaman dan pengembalian, 4.) menginput data buku tamu, 5.) Mengisi menu polling.

Implementasi E-CRM pada website ini terdapat pada interaksi anggota dengan sistem, dimana anggota dapat melakukan proses pencarian buku, mengisi polling tentang website perpustakaan ini serta mengisi form buku tamu sebagai bentuk aspirasi terhadap hal yang ingin disampaikan terkait website yang telah dibangun. Sehingga diharapkan dapat menjadi penjembatan antara pengguna/anggota dengan petugas perpustakaan sehingga dapat terjalin hubungan baik antar kedua pihak.

2. Analisa Kebutuhan Sistem

a. Pengguna wajib melakukan login terlebih dahulu agar dapat mengakses website perpustakaan digital. Username yang diinput pertama kali adalah NIM/NIK serta menginput password standar agar kerahasiaan masing-masing pengguna tetap terjaga keamanannya.

b. Sistem dapat melakukan konfirmasi form modul agar data-data yang masuk terjaga kualitas datanya.

c. Sistem akan melakukan kalkulasi terhadap data peminjaman yang dilakukan anggota.

d. Sistem akan menyimpan data polling yang telah dilakukan pengunjung website

e. Sistem dapat menampilkan grafik hasil polling

\subsection{Rancangan Database}




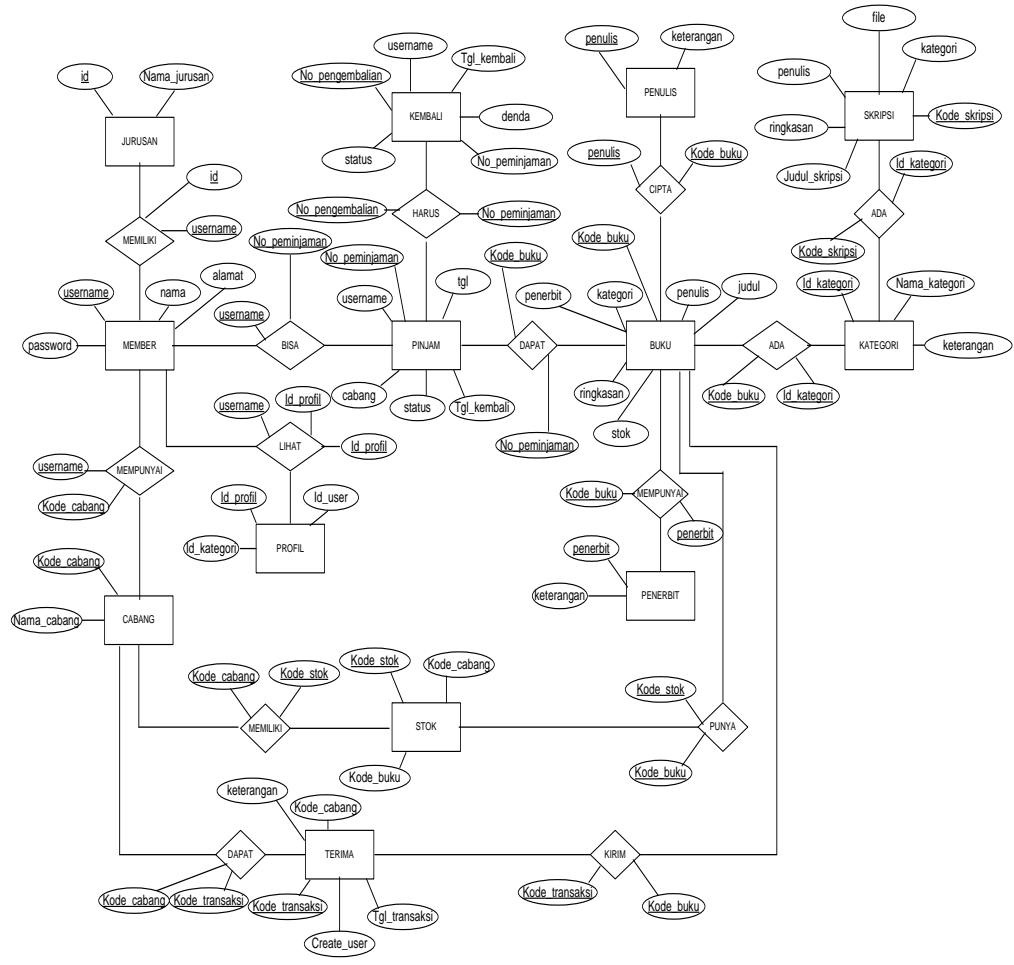

Gambar 2 Entity Relationship Diagram Perpustakaan

3.3 Use Case Diagram Perpustakaan

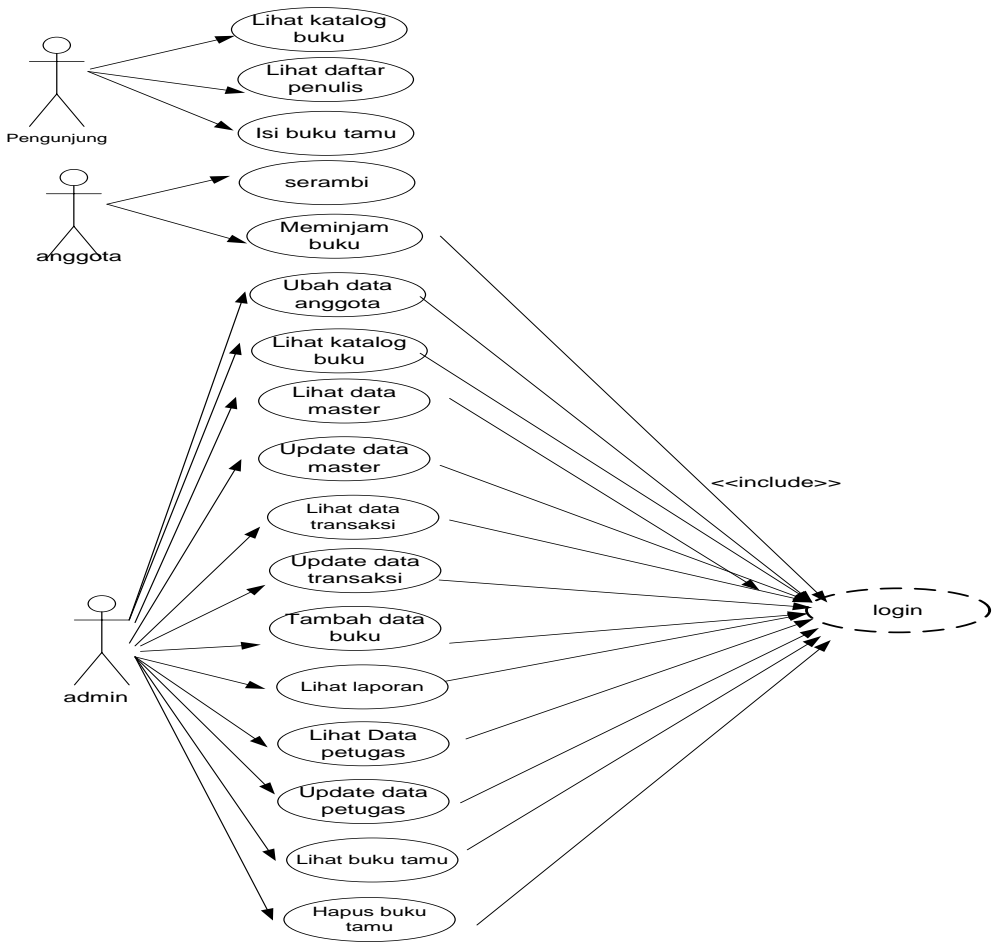

Gambar 3 Use Case Diagram Perpustakaan 
3.4 Desain Implementasi Program

1. Tampilan Menu Utama

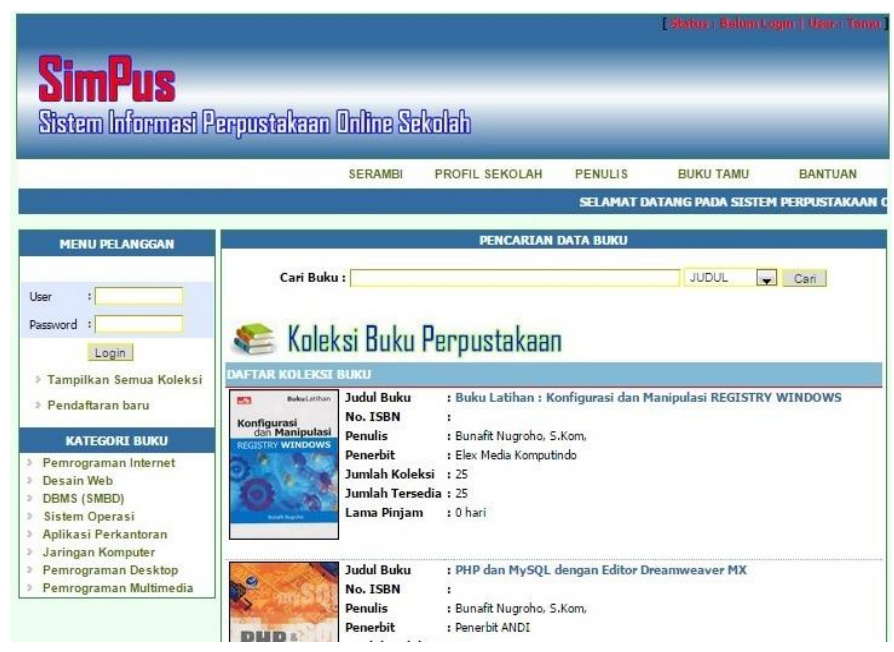

Gambar 4 Tampilan Menu Utama

Gambar diatas adalah tampilan menu utama pengunjung dari perpustakaan digital Sekolah Gema Nurani. Pada halaman ini, pengunjung dapat melihat profil, melihat cara pendaftaran, melihat katalog buku, mendaftar sebagai anggota, mengisi buku tamu, serta melakukan login sebagai anggota.

2. Tampilan Menu Pendaftaran Anggota

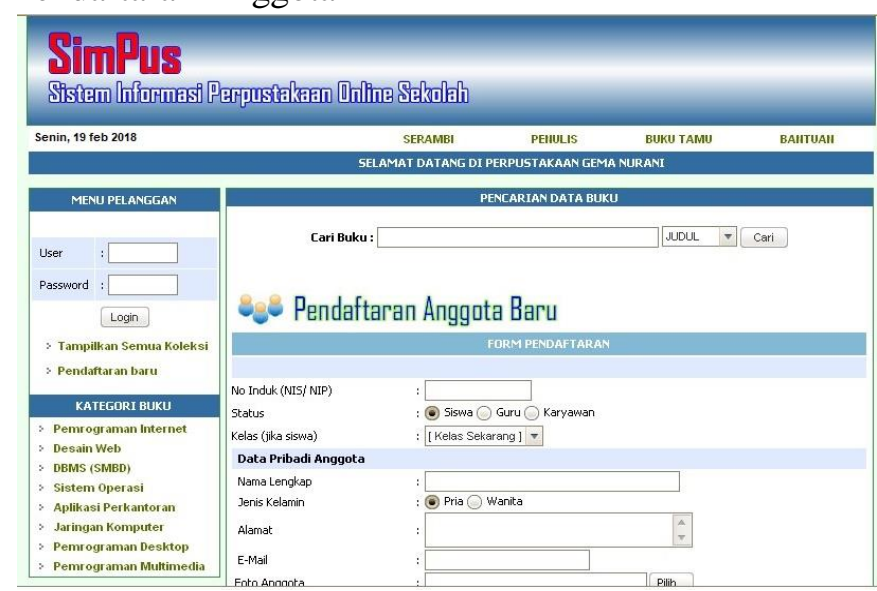

Gambar 5 Tampilan Menu Pendaftaran Anggota

Pada menu ini, pengunjung dapat melakukan pendaftaran sebagai anggota baru. 
Implementasi E-CRM Berbasis Web ...

3. Tampilan Menu Pencarian Buku

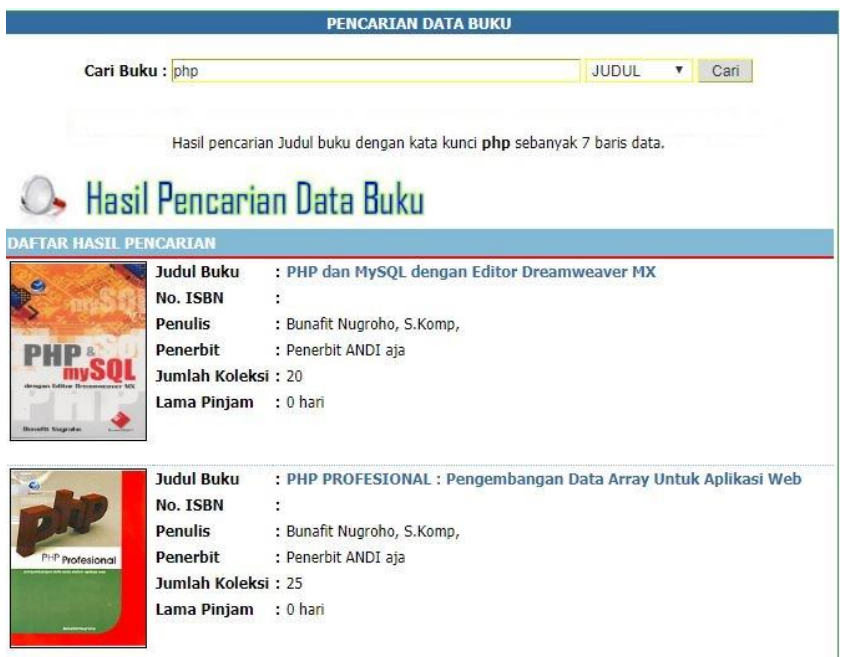

Gambar 6 Tampilan Menu Pencarian Buku

4. Tampilan Menu Login Anggota

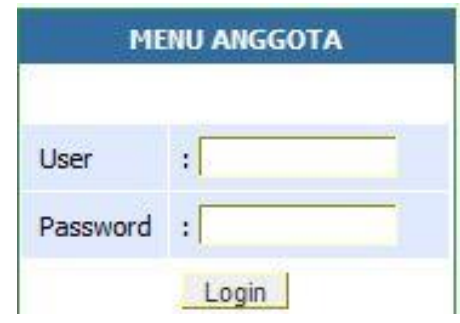

Gambar 7 Tampilan Menu Login Anggota

Pada menu ini, pengunjung yang telah mendaftar sebagai anggota dapat melakukan login untuk masuk ke sistem sebagai anggota perpustakaan.

\section{Tampilan Menu Utama Anggota}

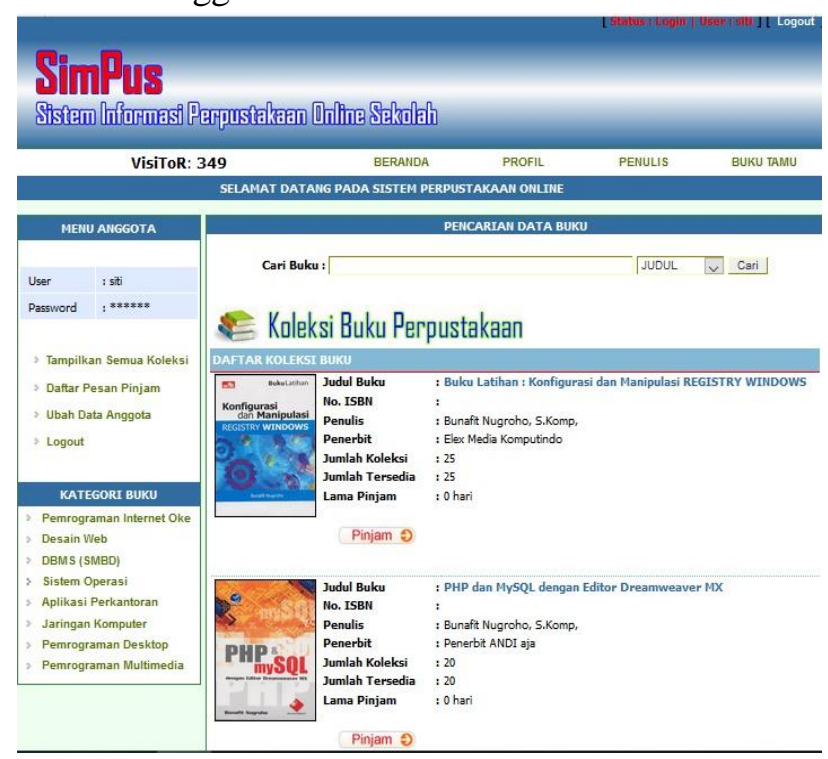

Gambar 8 Tampilan Menu Utama Anggota 
Pada menu ini, terdapat menu pencarian buku, kategori buku, serta menu edit data pribadi anggota.

6. Tampilan Menu Peminjaman Buku

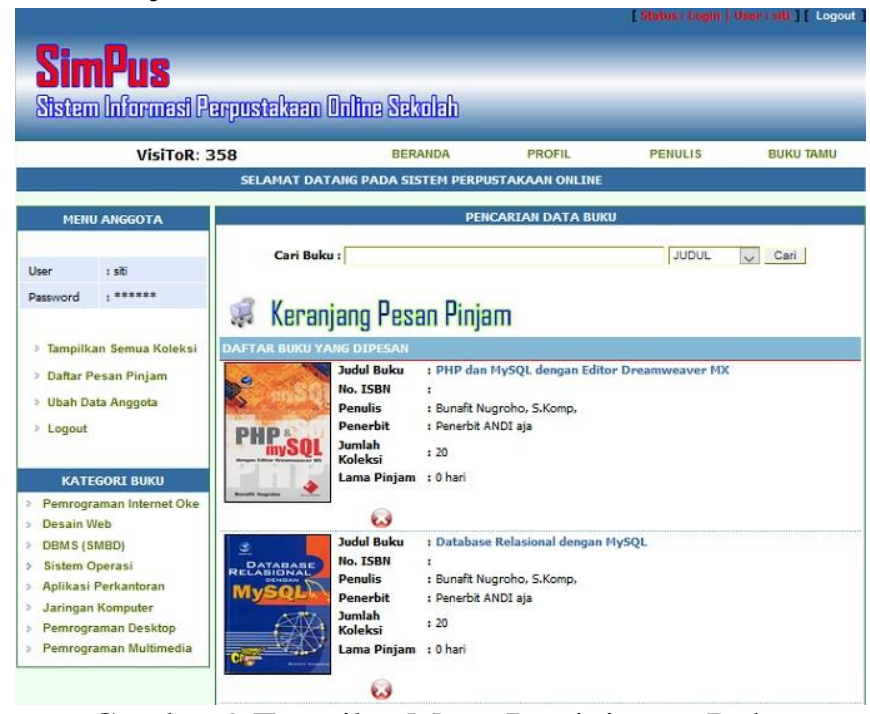

Gambar 9 Tampilan Menu Peminjaman Buku

Pada menu ini, anggota dapat melakukan peminjaman buku.

7. Tampilan Menu Polling

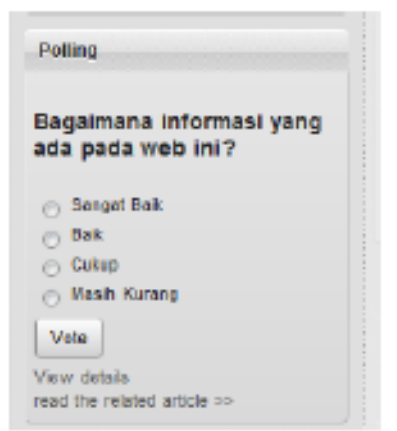

Gambar 10 Tampilan Menu Polling

Polling digunakan untuk mengetahui respon dari pengunjung serta anggota perpustakaan sebagai acuan untuk pengingkatan pelayanana dari pihak perpustakaan. Jumlah polling juga dapat mengetahui banyaknya pengunjung web perpustakaan ini.

\section{Tampilan Menu Kontak Kami}

Kontak Kami
Hallo, Ada yang bisa kami Bantu ?? Hubungi Kami di :
Perguruan Islam Terpadu Gema Nurani
॥ Raya Kaliabang Tengan No 75B, Bekasi Utara
Telp : 021-88871329

Gambar 11 Tampilan Menu Kontak Kami

Menu kontak kami dibuat agar dapat menciptakan terwujudnya dan terjalin komunikasi yang baik antar petugas perpustakaan dengan anggota perpustakaan sebagai bentuk loyalitas pelanggan. 
9. Tampilan Menu Buku Tamu

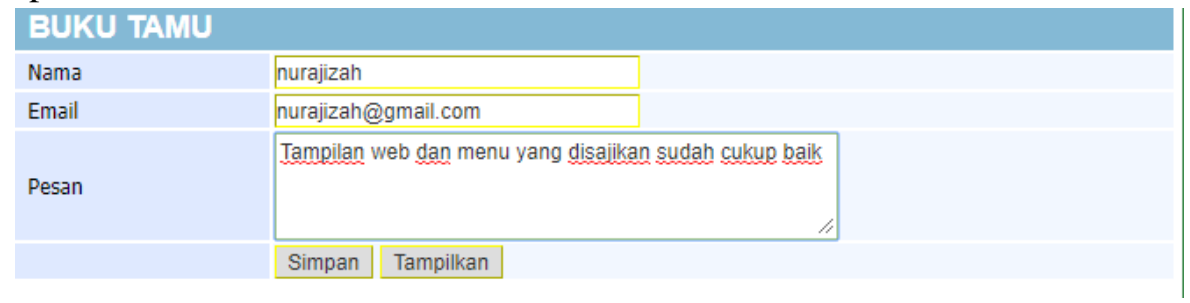

Gambar 12 Tampilan Menu Buku Tamu

Pada menu ini pengunjung dapat menyampaikan aspirasinya tentang website sebagai bentuk apresiasi terhadap pelayanan yang diberikan oleh petugas maupun sistem dari website perpustakaan ini

10. Tampilan menu grafik

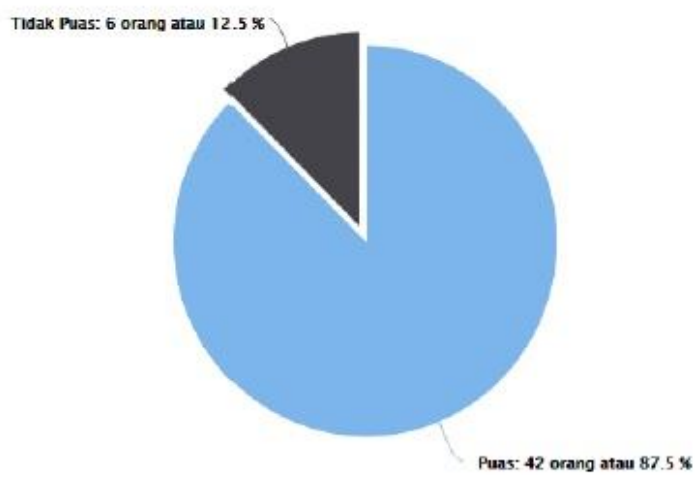

Gambar 13 Tampilan Menu Grafik

Dari grafik yang ditampilkan dapat diketahui seberapa puas pengguna dengan website yang telah mereka kunjungi dan pergunakan ini.

\section{KESIMPULAN} berikut:

Berdasarkan penelitian yang telah dilakukan, maka terdapat beberapa kesimpulan sebagai

a. Implementasi E-CRM yang dibuat terlihat dengan dibuatnya menu atau konten baru dari website perpustakaan digital Gema Nurani, yaitu menu pencarian buku yang memudahkan pengunjung mencari buku yang diinginkan.

b. Adanya menu polling yang merupakan menu baru dari website perpustakaan Gema Nurani menjadi tolak ukur bagi pengelola website serta petugas perpustakaan agar lebih memahami keinginan pengunjung website tersebut serta jika terdapat ketidakpuasan pengunjung maupun anggota dapat dilakukan evaluasi secara cepat dan tepat.

c. Menu buku tamu yang merupakan menu baru juga yang disajikan dalam website perpustakaan Gema Nurani juga dapat menjadi bahan masukan bagi pengelola perpustakaan untuk selalu mengetahui apa yang diinginkan pengunjung/anggota perpustakaan sebagai bentuk apresiasi peningkatan pelayanan perpustakaan digital Gema Nurani.

d. Dengan adanya E-CRM, pengguna perpustakaan akan mendapatkan informasi serta pembaharuan data secara tepat waktu. Hal ini dapat menjadi salah satu daya tarik minat membaca para pengunjung pada umumnya serta anggota perpustakaan pada khusunya. 


\section{SARAN}

berikut:

Untuk pengembangan penelitian selanjutnya, maka penulis memberikan saran sebagai

e. Perlunya peningkatan keamanan jaringan pada database yang dibuat agar tidak dapat diakses oleh pihak yang tidak bertanggung jawab serta tidak berkepentingan terhadap data tersebut.

f. Kontroling dan pengembangan sistem perlu dilakukan secara berkala sehingga e-crm yang digunakan dengan baik serta dapat menjadi sarana pemenuhan kebutuhan informasi bagi pengguna website.

\section{UCAPAN TERIMA KASIH}

Penulis mengucapkan terima kasih kepada Allah SWT atas rahmat Nya sehingga penelitian ini dapat terselesaikan dengan baik. Rekan-rekan dosen Universitas Bina Sarana Informatika atas sumbangsih saran yang diberikan.

\section{DAFTAR PUSTAKA}

[1] Wijaya, S. F., \& Darudiato, S, 2009, ERP(Enterprise Resource Planning) \& Solusi Bisnis. Yogyakarta, Graha Ilmu.

[2] Afrina, M., \& Ibrahim, A,. 2013, Rancang Bangun Electronic Costumer Relationship Management (E-CRM) Sebagai Sistem Informasi Dalam Peningkatan Layanan Perpustakaan Digital Fakultas Ilmu Komputer Unsri. Jurnal Sistem Informasi (JSI), No.2, Vol.5, 629-644.

[3] Purwanto, H., Sumbaryadi, A., \& Sarmadi, S. 2018. E-Crm Berbasis Web Pada Sistem Informasi Penjualan Funiture. Jurnal Pilar Nusa Mandiri, No.1, Vol 14, 15-20.

[4] Muchsam, Y., 2018, Pengembanagn sistem Informasi Kerawanan Pangan Berbasis SMS Gateway Dengan Menggunakan Metode FAST(Framework For The Applications Of System Thingking). Jurnal E-komtek, No.1., Vol.1, 99-111.

[5] Afrina, M., \& Ibrahim, A. 2012, Pengembangan Model Sistem Informasi Perpustakaan dengan Teknologi Informasi Berbasis Wireless Aplication Protocol(WAP) pada Universitas Sriwijaya. Sistem Informasi, No.1, Vol.4, 425-43.

[6] Kosasih, A., 2009, Otomasi Perpustakaan Sekolah: sebuah pengenalan. Jurnal Perpustakaan Sekolah, No.1, Vol.1, 1-13.

[7] Dyantina, O., Afrina, M., \& Ibrahim, A., 2012, Penerapan Customer Relationship Management (CRM) Berbasis Web (Studi Kasus Pada Sistem Informasi Pemasaran di Toko YEN-YEN), Jurnal Sistem Informasi, No.2, Vol 4, 516-529, 2012.

[8] Lestari, I., \& Irawan, H. 2017, Analisis Dan Desain Electronic Customer Relationship Management ( E- Crm ) Berbasis Web Guna Membina Serta Meningkatkan Loyalitas Penyewa Studi Kasus : Pt . Sari Indah Lestari ( Sil ) - Mall Cbd Ciledug. Jurnal CKI on Spot. No.2, Vol.10, 47-53. 